\title{
Teknik Hand Tracking Menggunakan Metode Inverse Kinematics Pada Pembuatan Animasi 3D
}

\author{
Slamet Pamujianto ${ }^{1}$, M. Suyanto ${ }^{2}$, Amir Fatah Sofyan $^{3}$ \\ 1'aan.slamet.pamujianto@gmail.com, ${ }^{2}$ yanto@amikom.ac.id, ${ }^{3}$ amir@amikom.ac.id \\ Program Studi Magister Teknik Informatika Universitas Amikom Yogyakarta,
}

\begin{abstract}
D animation production stage is growing. Many new techniques apply to each production process. Not a lot of animation production that uses new techniques, thus allowing production houses to perform such techniques as one way to improve the quality of animation production in the country. One technique that is often used in producing $3 D$ animation is the motion tracking. Hand tracking technique is one of motion tracking technique that focuses more on hand organ. Motion Tracking is a process in getting the tracker from marker a footage that has been paired marker. Markers generated from the motion tracking process can be referred to as a tracer. Tracer can be connected with $3 D$ objects that have complete modeling and rigging. So it can generate an animation of the tracer movement that was hung with a $3 d$ bone modeling. Using the inverse kinematics method approach is done to improve when the animation produced is more controlled movement and by adding DOF (Degree Of Freedom) in every space of motion model that has been connected tracer with bone (bone) riggingnya avoid animation movement out of the path.
\end{abstract}

Intisari- Tahap produksi animasi 3D semakin berkembang. Banyak teknik - teknik baru yang terapk an pada setiap proses produksinya. Belum banyak produksi animasi yang menggunakan Teknik baru, sehingga memungkinkan rumah produksi dapat melakukan Teknik tersebut sebagai salah satu cara meningkatkan kualitas produksi animasi di dalam negeri. Salah satu Teknik yang sering digunakan dalam memproduksi animasi 3D adalah motion tracking. Teknik hand tracking merupakan salah satu dari Teknik motion tracking yang lebih berfokus pada organ tangan. Motion Tracking merupakan sebuah proses dalam mendapatkan tracker dari marker sebuah footage yang telah dipasangkan marker. Marker yang dihasilkan dari proses motion tracking dapat disebut sebagai tracer. Tracer dapat dihubungkan dengan objek 3D yang telah lengkap modeling dan rigging. Sehingga dapat menghasilkan animasi dari pergerakan tracer yang terhunbung dengan bone modeling $3 \mathrm{~d}$. Menggunakan pendekatan metode inverse kinematics dilakukan untuk memperbaiki pada saat animasi yang dihasilkan lebih terkontrol pergerakannya dan dengan menambahkan DOF (Degree Of Freedom) pada setiap ruang gerak model yang telah terhubungkan tracer dengan bone (tulang) riggingnya menghindari gerakan animasi keluar dari jalurnya.

Kata Kunci- Hand Tracking, Inverse Kinematics, DOF (degree Of Freedom), 3D

\section{PENDAHULUAN}

Pergerakan tangan manusia itu cukup tangkas, dinamis dan kompleks mampu melakukan pergerakan yang sistematis misalnya dalam proses mengetik, bermain piano, bermain gitar dan mungkin digunakan untuk ko munikasi bahasa isyarat [1]. Bagi beberapa orang yang mempunyai gangguan penglihatan, pendengaran dan tunawicara tangan merupakan anggota badan yang utama dalam melakukan berbagai kegiatan. Melihat keutamaan organ tubuh penting ini, beberapa tahun belakangan ini banyak studi tentang pemanfaatan tangan sebagai input device salah satunya adalah Teknik hand tracking yang untuk berbagai kebutuhan di berbagai bidang baik itu di industri film, game, robotika ataupun untuk pengembangan HCI (Human Computer Interaction).

Dalam salah satu proses dalam pemanfaatan teknologi penangkapan gerakan manusia untuk mendapatkan animasi termasuk didalamnya hand tracking dengan semakin inovatif perkembangannya teknologi komputer mampu mempermudah dalam proses memproduksi film animasi yang realistik. Memproduksi animasi gerakan tangan yang realistik dapat dihasilkan dengan teknologi komputer salah satunya adalah menerapkan Teknik motion tracking atau motion capture. Huang, 2016 mengungkapkan bahwa 3D Motion Tracking adalah teknologi kunci dalam realitas maya serta bidang terkait lainnya seperti animasi ko mputer, antarmu ka pengguna 3D, robotika, dan sebagainya [2]. Pada penelitian Purwanto, 2014 mengemukakan dalam penelit iannya menjelaskan bahwa Motion Tracking merupakan Teknik yang digunakan untuk mengambil koordinat titik posisi dalam sebuah adegan gerak sehingga ketika dimasukkan objek akan bergerak dengan sempurna [3].

Dalam motion tracking yang hanya menangkap pergerakan tangan yaitu hand tracking. Pada perkembangannya Teknik motion tracking itu dibagi menjadi dua jenis yaitu motion tracking menggunakan marker dan motion tracking tanpa marker (markerless). Pengembangan motion tracking tanpa marker memang sedang sedang meningkat pada saat ini, namun motion tracking dengan marker memiliki keunggulan dibandingkan markerless menurut penelitian Sebastian Schröder, dkk. 2017 mengemukakan bahwa motion capture berbasis optical marker, atau mocap, secara luas dianggap sebagai metode standar untuk memperoleh gerakan pemain manusia baik dalam konteks penelitian maupun industri atau hiburan [6]. Meskipun ada banyak solusi alternatif untuk pelacakan gerak, seperti metode tanpa markerless atau sistem yang menggunakan sensor inersia tidak digunakan secara luas 
karena keandalan sistem berbasis marker.

Proses pengambilan animasi hand tracking menggunakan marker untuk mendapatkan pergerakan objek 3D tergantung dari efektifitas penanda yang tertangkap dan akan diolah menjadi animasi 3D yang baik. Selain itu menurut penelitian [2] menyatakan ada beberapa faktor yang perlu diperhatikan untuk menghasilkan motion tracking yang baik diantaranya harus menyusun stage, marker, lighting, peralatan kamera dan menentukan pergerakan dalam proses perekaman. Untuk mengurangi kesalahan gerak dalam proses penganimasian objek 3D khususnya pada pergerakan jari dan tangan diperlukan pendekatan metode pergerakan kinematik, disertai pula dengan membatasi gerak atau disebut dengan DOF (Degree Of Freedom). Faktor tersebut mempengaruhi bagus tidaknya animasi otomatis yang dihasilkan, animasi oto matis yang dimaksud adalah pergerakan objek 3D yang terkoneksi dengan marker dari hasil proses pengolahan menggunakan software.

Terdapat dua metode kinematika / kontrol gerak yang biasa digunakan dalam robotika namun Teknik tersebut dapat diberlakukan pada animasi 3D yaitu Inverse Kinematics dan Forward Kinematics. Forward kinematics kalau dalam robotika digunakan untuk menentukan posisi dan orientasi end effector apabila sudut joint - nya telah diketahui. Variabel sudut joint yang diberikan diubah ke dalam posisi dan orientasi end effector yang ditujukan untuk koordinat referensi. Untuk menganimasi tangan maka metode forward kinematics kurang cocok karena hanya untuk pergerakan rotasi. Namun berbeda dengan metode inverse kinematics merupakan metode turunan dari forward kinematik, jika forward kinematik dengan menentukan sudut putar rotasi untuk mendapatkan titik tujuan maka pada inverse kinematik berlaku sebaliknya. Metode ini akan langsung menentukan titik tujuan dan sudut putar rotasinya akan mengikuti.

Dalam penelitian Nugraha, dkk., 2015 mengatakan bahwa metode Inverse Kinematik memungkinkan pembuat untuk membuat gerakan yang lebih cepat tanpa harus membuat gambar yang banyak [5]. Pada penelitian ini akan diterapkan metode inverse kinematik dengan pembatasan derajat kebebasan atau Degree Of Freedom (DOF) untuk membuat sebuah posisi gerakan berdasarkan pergerakan dari marker hasil tracer dalam proses hand tracking sehingga dapat menghasilkan animasi gerakan tangan yang realistis meskipun dengan marker yang cukup minimal.

\section{TINJAUAN PUSTAKA}

Teknik Motion Tracking merupakan salah satu Teknik proses visual efek, selain Teknik masking, keying. Dunia efek visual atau CGI (Computer Grapich Imagery) telah diterapkan diberbagai bentuk sajian video seperti TV commercial maupun film layar lebar. Bisa dikatakan CGI merupakan revolusi film era modern. Menurut penelitian [3] ada beberapa pertimbangan dalam film menggunakan teknologi CGI diantaranya sebagai berikut : biaya yang relative murah, efektifitas kerja dan kreatifitas tanpa batas. motion tracking merupakan salah satu penyebutan untuk Teknik motion capture yaitu suatu Teknik yang digunakan untuk mencari titik objek dari sebuah footage untuk membuat gambar gerak (motion capture). Footage objek yang digunakan dapat berupa rekaman gerakan yang sudah ditanamkan penanda (marker) ataupun tanpa (markerless).

Pada perkembangannya penelitian tentang penggunaan motion tracking menjadi lebih detail pada bagian - bagian tertentu dari tubuh manusia. Teknik hand tracking yang peneliti akan kerjakan merupakan salah satu cabang dari Teknik motion tracking yang lebih spesifik pada organ tangan pada manusia untuk mendapatkan tracer atau penanda sebagai titik acuan dalam menggerakkan objek 3D.

\section{A. Cara Kerja Motion Tracking}

Dalam penelitian Purwanto, 2014 menjelaskan bahwa sebuah tracer menganalisis daerah piksel frame dalam klip video kemudian menguncinya menjadi pola dalam melintasi kanvas [3]. Dari proses footage yang dilakukan akan dipengaruhi oleh kontras yang tinggi untuk mendapatkan tracer yang ideal, rinci dan konsisten. Hasil dari proses pengolahan tracer tersebut akan disimpan pola posisi sesuai dengan rujukan. Posisi yang dihasilkan dari proses tracer ini mengacu pada 3 sumbu yaitu $x, y$ dan $z$ sehingga gerakan animasi yang dihasilkan dari pola tersebut dapat berupa skala, rotasi dan posisi.

\section{B. Pengertian Kinematika}

Pengertian Kinematika didefinisikan sebagai "study" gerak: cabang dari fisika yang berhubungan dengan system gerak tanpa referensi untuk kekuatan dan massa. Sebuah model kinematic dibangun dengan segmen dan sendi dalam struktur hierarkis yang disebut dengan hierarki orangtua dan anak. Famukhit, dkk. Pada tahun 2016 menyampaikan Kinematik terdiri dari 2 pendekatan yaitu Inverse kinematik (IK) dan Forward kinematik (FK). Animasi menggunakan dua pendekatan ini untuk menampilkan hasil yang natural [7]

\section{DOF (Degree Of Freedom)}

Derajat kebebasan dari sistem mekanika adalah jumlah parameter independen yang menentukan konfigurasi, untuk berbagai fungsi yang menentukan keadaan sistem fisik dan analisis sistem tubuh pada Teknik mesin, Teknik penerbangan, Teknik robotika dan rekayasa structural. Pada sistem mekanika gerak tangan memiliki gabungan DOF yang merupakan jumlah DOF dari tangan, sedikit kendala internal yang mungkin ada pada gerakan relative.

\section{METODOLOGI PENELITIAN}

\section{A. Metode Penelitian}

Teknik motion tracking in i merupakan sebuah sistem yang sudah ada dan sudah dikembangkan untuk dikomersilkan, namun Teknik ini memerlukan biaya yang besar dalam prakteknya dengan berbagai Teknik yang ada sekarang ini masih perlu dikembangkan dan diperbanyak untuk efisiensi biaya salah satu dari proses produksi film animasi khusunya di Indonesia.

Karena alasan tersebut akan menggunakan metode Explorative Experimental yaitu percobaan berbagai macam pengambilan gambar dengan berbagai background agar nantinya dapat dilakukan proses motion tracking dengan inverse kinematik untuk menghasilkan gerakan otomotis. Selain itu untuk menyempurnakan hasil penelitian penulis menambahkan metode pengumpulan datanya dengan metode yang lain. 


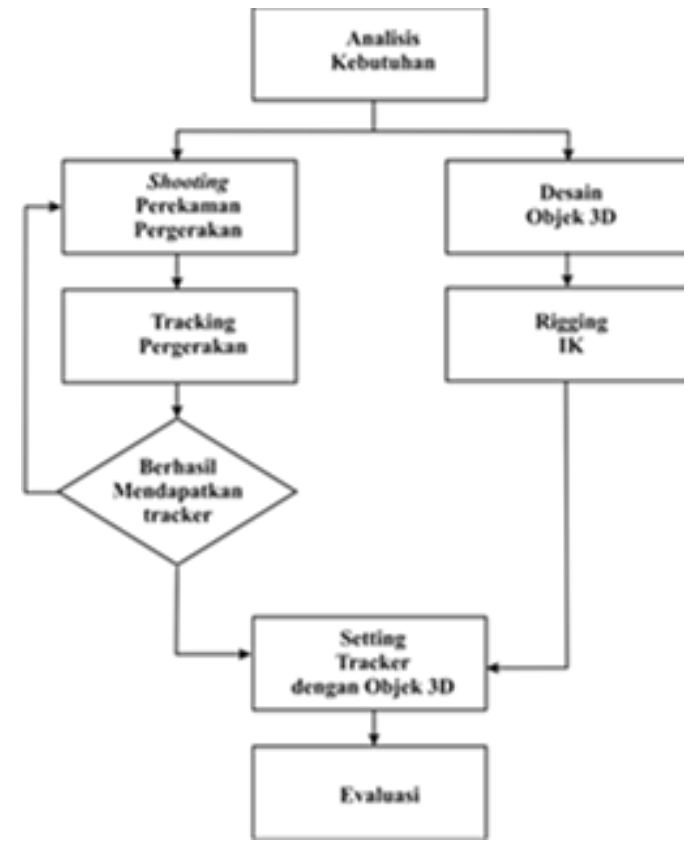

Gambar 1 Alur Penelitian

Dalam proses mengenali penanda ini sumber objek gerakannya adalah marker dari video tangan yang digerakkan berdasarkan skenario peneliti dan telah dalam bentuk file rekaman video. Dalam pengaplikasian Teknik hand tracking peneliti menggunakan metode Inverse Kinematik.

\section{B. Metode Pengumpulan Data}

Pengumpulan data digunakan dalam memperoleh datadata yang dibutuhkan dalam menyusun penelitian ini. Adapun metode pengumpulan data yang digunakan adalah dengan metode primer yaitu dengan observasi dan wawancara. Metode Skunder dengan studi literatur dan dokumentasi.

\section{Alur Penelitian}

Adapun garis besar urutan penelitian adalah sebagai berikut :

1) Analisis Kebutuhan : Tahap dimana persiapan akan kebutuhan fungsional maupun kebutuhan non fungsional

2) Pengambilan Gambar : Tahap dimana pengambilan gambar untuk perekaman video dilakukan untuk mendapatkan titik marker

3) Proses Motion Tracking :Merupakan kegiatan melacak titik dari proses pergerakan video rekaman yang sudah dipasangkan marker, yang kemudian hasil tracking tersebut disimpan dalam bentuk keyframe berurutan

4) Proses Pembuatan Objek 3D: Merupakan tahap pembuatan objek 3D berupa tangan

5) Penulangan atau Rigging Inverse Kinematik : Hasil dari objek 3D kemudian dilakukan proses pembuatan tulang dengan inverse kinematik

6) Penerapan hasil tracking : Pada tahap ini hasil data tracking yang didapat dari rekaman video kemudian diterapakan dalam objek 3D

7) Evaluasi : Tahap untuk melihat kesesuaian dengan kebutuhan fungsional untuk mengetahui apakah rancangan berjalan sesuai dengan rencana awal dengan hasil penilaian pakar

\section{HASIL DAN PEMBAHASAN}

\section{A. Analisis dan Perancangan Sistem}

1) Analisis Kebutuhan Fungsional : Dari fitur yang telah tersedia tersebut penulis mengklasifikasikan beberapa kebutuhan fungsional yang diperlukan untuk menghasilkan gerakan animasi yang sesuai dengan pergerakan rekaman tangan pada video. Adapun kebutuhan fungsional tersebut antara lain: Animasi yang dihasilkan harus tanpa pembuatan keyframe secara manual oleh animator, Pergerakan animasi objek tangan 3D harus sesuai dengan referensi pergerakan tangan rekaman video, Pergerakan sendi - sendi karakter modeling 3D harus sesuai dengan pergerakan sendi tangan manusia, Durasi waktu harus sama dengan durasi referensi video rekaman, Pergerakan harus melibatkan multilayer, Pergerakan menggunakan inverse kinematics, Penanda seminimal mungkin dan Penggunaan Degree Of Freedom.

2) Analisis Jumlah Ruas Sendi : Analis is ju mlah ruas sendi dilakukan untuk mengetahui berapa banyak sendi yang

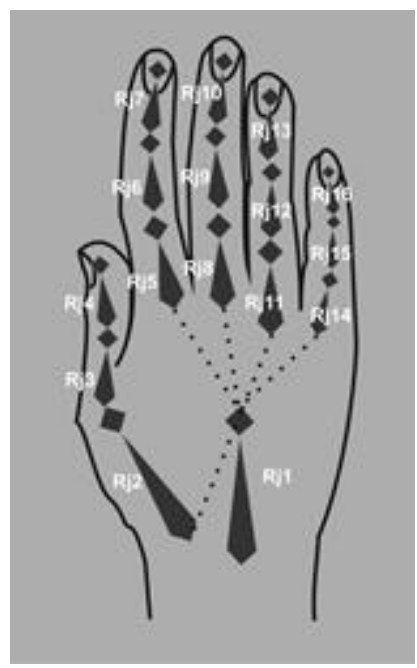

Gambar 2 Ruas Sendi

terdapat pada jari-jari tangan. Penentuan jumlah sendi ruas setiap jari tangan diberikan penamaan sesuai dengan urutan ruas jari pada masing-masing nama jari sesuai dengan struktur anatomi jari tangan. Hasil dari analisa penghitungan ini untuk digunakan sebagai referensi dan mempermudah dalam proses pemasangan tulang (bone) pada simu lasi gerak tangan. Untuk melihat cara pengukuran dan hasilnya dapat dilihat pada gambar 2

3) Analisis Derajat Sendi : Analisis derajat sendi dilakukan bertujuan untuk mengetahui derajat kebebasan (degree of freedom) tulang sendi pada jari-jari tangan. Pengukuran derajat kebebasan dilakukan pada sendi putar pangkal jari, sendi putar ruas kedua, sendi putar ruas ke tiga dan untuk gerakan sendi putar rotasi sumbu $\mathrm{z}$ pada masingmasing jari. Pengukuran derajat kebebabasan dilakukan dengan busur sebagai alat pengukuran. Pengukuran pada gerakan jari tangan dilakukan dengan mengukur sudut pangkal jari tangan dari sumbu koordinat $0^{0}$ atau $180^{\circ}$ kemudian tangan digerakkan ke batas paling atas atas dan ke batas paling bawah, pengukuran pada ruas jari kedua dan ketiga dilakukan dengan cara yang sama. Pengukuran untuk sudut gerakan jari tangan ke samping di lakukan dari pangkal jari atas dari sumbu koordinat $0^{0}$ atau $180^{\circ}$ dan arah 
pergerakan tangan. Untuk melihat cara pengukuran dan hasilnya dapat dilihat pada gambar 3 .

4) Analisis Perancangan Gerakan : Analisis pergerakan jari - jari tangan dilihat dari pengamatan kompleksitas pergerakan tangan pada umumnya tangan bergerak. Analisa gerakan tangan dilakukan untuk mendapatkan gerakan animasi yang sesuai harapan penulis dan sesuai dengan video rekaman referensi. Pengamatan kompleksitas gerak tangan dilakukan dengan mengambil gambar untuk direkam ke dalam bentuk video pada tangan seorang peraga. Pada beberapa pemilihan gerak yang ditentukan yaitu setiap pergerakan tangan diawali dengan posisi tangan terbuka telapaknya kemudian baru menggerakkan jari secara acak, membuat membuat bentuk gerakan tangan menggenggam, memperagakan tangan mengambil spidol kemudian menggenggamnya dan yang terakhir yaitu mengambil cangkir dan mengangkatnya.

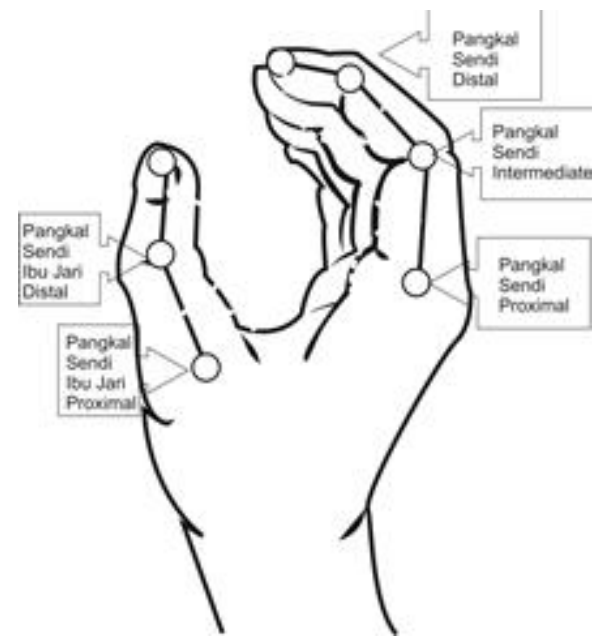

Gambar 3 Perancangan Derajat Sendi

5) Analisis Perancangan Lokasi Marker : Analisa perancangan lokasi marker merupakan proses memprediksi posisi marker yang paling cocok dengan gerakan yang akan dilakukan. Pertimbangan pergerakan model, warna dan bentuk marker mempengaruhi keberhasilan dalam proses ini. Dalam proses memprediksi lokasi marker yang tepat belum ada standar penerapan umum. Menurut penelitian [4] setting marker ditempelkan pada sendi model referensi, sehingga pada penelitiannya marker dilekatkan pada ujung kaki, mata kaki, lutut, pangkal paha, perut, dada atas, leher kepala, pundak siku dan ujung kepalan tangan. Pada umumnya untuk pemasangan marker ada di setiap sendi, pada penelitian ini peletakan marker di setiap sendi rotasi jari tangan model referensi dan beberapa marker pada ujung jari untuk mengatisipasi oklusi, sehingga ju mlah marker hanya dipasang pada setiap ruas tulang berjumlah 30 , seperti pada gambar 4 .

6) Analisis Perancangan Tangan Objek $3 D$ : Perancangan modeling tangan pada penelitian ini menggunakan model primitive modeling. Dalam pembuatannya dibuat semirip mungkin dengan bentuk tangan pada hasil rekaman video pergerakan. Untuk modeling tangan yang mirip diperlukan gambar referensi awal agar supaya model tangan yang dibuat dalam bentuk karakter 3D proporsional untuk dipasangkan dengan gambar aslinya.

7) Analisis Perancangan Struktur Tulang : Analisis perancangan stuktur tulang disesuaikan dengan susunan nama pada penghitungan ruas sendi mengikuti struktur anatomi pergerakan jari tangan. Hal ini digunakan untuk mempermudah penulis dalam proses pembuatan tulang pada jari-jari tangan. Pembuatan struktur tulang berdasarkan hasil

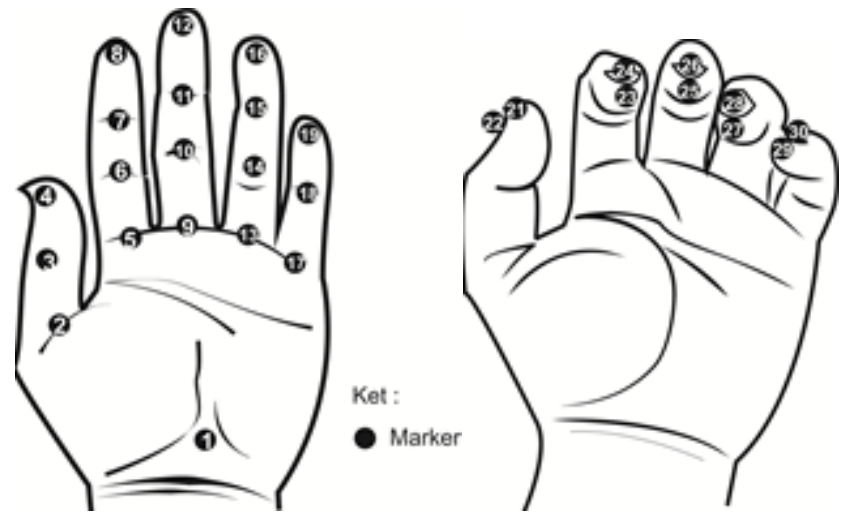

Gambar 4 Perancangan Lokasi Marker

analisis ruas sendi. Susunan struktur tulang jari-jari tangan seperti gambar 5.

8) Analisis Fitur Aplikasi :Proses Hand Tracking dan Implementasi Animasi 3D ini dapat dipermudah dengan menggunakan sofware 3 dimensi Blender yang telah dilengkapi beberapa fitur Motion Tracking, DOF (Degree Of Freedom dan Inverse Kinematics.

\section{Implemantasi}

1) Peralatan yang digunakan : Dalam proses pengambilan gambar penggunaan kamera tidak memerlukan kamera yang khusus. Kamera yang penulis gunakan dalam penelitian ini yaitu Kamera DSLR Canon EOS 1200D. Tripod merupakan penyangga untuk kamera. Hal ini digunakan supaya saat pengambilan gambar kamera tetap fokus dan stabil, Penggunaan lampu LED merupakan untuk memberikan pencahayaan ruangan. Alat ini berfungsi supaya saat pengambilan gambar dapat mengurangi bayangan yang ditimbulkan, Marker merupakan penanda yang dibuat menggunakan bahan sticker label dengan dibubuhkan titik lingkaran. Marker yang peneliti gunakan menggunakan bahan yang sederhana dan berupa sticker sehingga tidak terlepas saat dilekatkan pada permukaan tangan. Sticker label sudah dibubuhkan titik berupa simbol lingkaran menggunakan spidol berwarna hitam dipotong kecil menggunakan gunting dengan bentuk dadu berukuran $0.5 \mathrm{~cm}$ x $0,5 \mathrm{~cm}$.

2) Proses Merekam Pengambilan Gambar: Sebelum proses pengambilan gambar ada pada objek tangan harus ditempelkan marker pada titik-titik strategis yang telah ditentukan. Titik strategis pada bagian jari-jari tangan terletak pada setiap ruas jari. Titik-titik tersebut merupakan prediksi skema tempat yang sangat potensial untuk menghasilkan tracer yang dapat menghasilkan gerakan rig yang sesuai dengan referensi rekaman gerakan tangan pada video. Pada praktek percobaan menggunakan settingan kamera untuk pengambilan gambar video adalah sebagaiberikut :

Kualitas Video : HD 1920x1080

Frame Rate : 25 Fps

ISO $\quad: 100-400$

Aperture $\quad: \mathrm{f} 1 / 2-\mathrm{f} 1 / 8$ 
Untuk settingan kamera bisa dirubah sewaktu - waktu sesuai dengan keadaan ruangan serta kualitas lighting yang tersedia. Jarak dan posisi pengambilan seperti gambar 6.

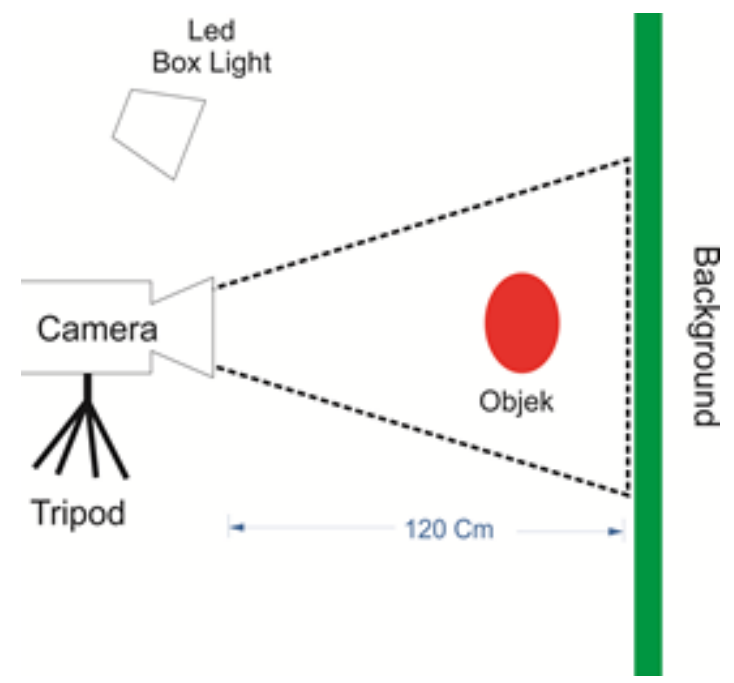

Gambar 6 Posisi perekaman

3) Proses Tracking : Proses tracking merupakan komputasi komputer menggunakan algoritma yang didesain sesuai dengan kebutuhan, tracker akan dihasilkan dari dalam proses merekam informasi tentang object of interest dalam bentuk gabungan dari image pixel, pembentukan informasi berhubungan dengan penampakan dari target tracking nilai pixeldan video tracker me mperkirakan lokasi dari objek yang ditracking terus menerus selama proses tracking terjadi. Cara me mperoleh informasi objek dan gerakan kamera berdasarkan dari hasil yang diperoleh dari frame video dimana tujuannya adalah untuk menemukan objek yang menarik dalam hal ini adalah marker yang telah terpasang dalam adegan. Untuk proses automatis tracking ini tergantung kemampuan software dalam membaca pergerakan titik yang menarik dalam proses perekaman, titik yang menarik yang dimaksud dalam hal ini adalah marker yang telah terpasang pada proses perekaman video dilakukan.

4) Desain Objek 3D : Teknik blueprint di blender dapat diterapkan dengan memasukkan image atau video referensi rekaman dalam proses pengambilan gambar. Dengan mengaktifkan properti yang berisi parameter umum objek, grid dan tampilan viewport termasuk dalam hal ini adalah image background seperti pada gambar 7 .

Dalam mendesain modeling ada beberapa tahap yang harus dilakukan penulis agar model objek 3D sesuai dengan gambar video rekeman referensi. Proses yang perlu dilakukan adalah sebagai berikut : Background Images : Proses ini dilakukan untuk mengatur tampilan image gambar tangan pada video yang ada sebagai (Blueprint) sebagai acuan dalam pembuatan modeling tangan 3D. Global Scale : Proses ini digunakan untuk melakukan proses scale objek modeling 3D dengan image yang ada. Edit Mode : Proses ini digunakan

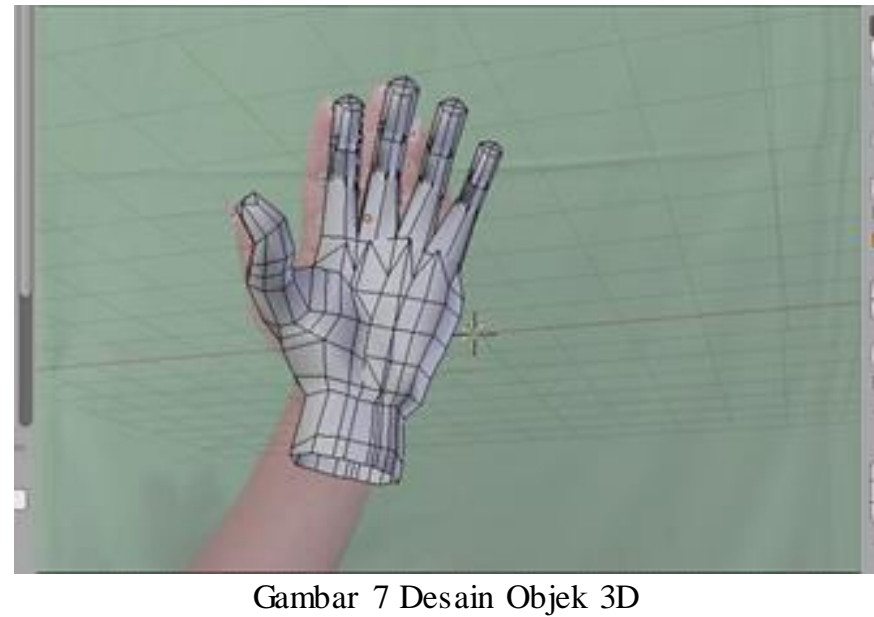

untuk merubah objek standar cube menjadi medel tangan sesuai dengan image background yang ada, Modifier Subdivision Surface : Proses ini digunakan untuk memodifikasi obejk 3D yang telah di buat supaya lebih halus.

5) Proses Rigging Objek 3D : Dalam merigging modeling ada beberapa tahap yang harus dilakukan agar rigging model objek 3D sesuai dengan gambar video rekeman referensi dan berhasil dengan baik. Proses yang perlu dilakukan adalah sebagai berikut : Pertama, Armature Bone : Proses ini awal dilakukan untuk membuat tulang. Kedua, Add Objek Constraint : Proses ini digunakan untuk menambahkan derajat kebebasan pergerakan tulang. Ketiga, Edit Mode : Proses ini digunakan untuk mengedit tulang. Dalam mode pengeditan terdapat dua pilihan yaitu edit mode untuk mengedit skala, rotasi dan posisi dan pose mode merupakan mode pengaturan untuk menggerakkan tulang berdasarkan titik 3 sumbu (x,y dan Z). Keempat, Property armature : Proses ini digunakan untuk mengaktifkan $\mathrm{x}$-ray berguna supaya ringging yang terpasang didalam objek masih dapat terlihat, axes untuk mengetahui posisi koordinat titik 3 sumbu dan nam untuk mengetahui nama setiap tulang. Teknik blueprint di blender dapat diterapkan dengan memasukkan image atau video referensi rekaman dalam proses pengambilan gambar. Dengan mengaktifkan properti yang berisi parameter umum objek, grid dan tampilan viewport termasuk dalam hal ini adalah image background.

\section{Menghubungkan Hasil Tracing Dengan Objek 3D}

Dalam menghubungkan dengan objek 3D ada beberapa tahap yang harus dilakukan agar proses sesuai dengan gambar video rekeman referensi dan berhasil dengan baik. Proses yang perlu dilakukan adalah sebagai berikut :Pertama, Add objek constraint inverse kinematics : proses ini digunakan untuk menambahkan inverse kiinematics sekaligus menghubungkan tracker dengan tulang. Kedua, Add objek constraint floor: proses ini digunakan untuk menghubungkan tracker dengan tulang bagian telapak kanan. 


\section{E. Analisis Hasil}

\section{- Pengujian Hasil Rancangan}

Analisis hasil merupakan pengujian rancangan implementasi hand tracking dengan invers kinematics untuk menghasilkan animasi otomat is objek tangan 3D mencakup kepada klasifikasi pengujian fungsional, dimana pengujian fungsional ini bertujuan untuk mengetahui apakah sudah berjalan sesuai dengan yang diharapkan sejak awal. Adapun kriteria rancangan yang akan diujikan antara lain : 1) Animasi yang dihasilkan harus tanpa pembuatan keyframe secara

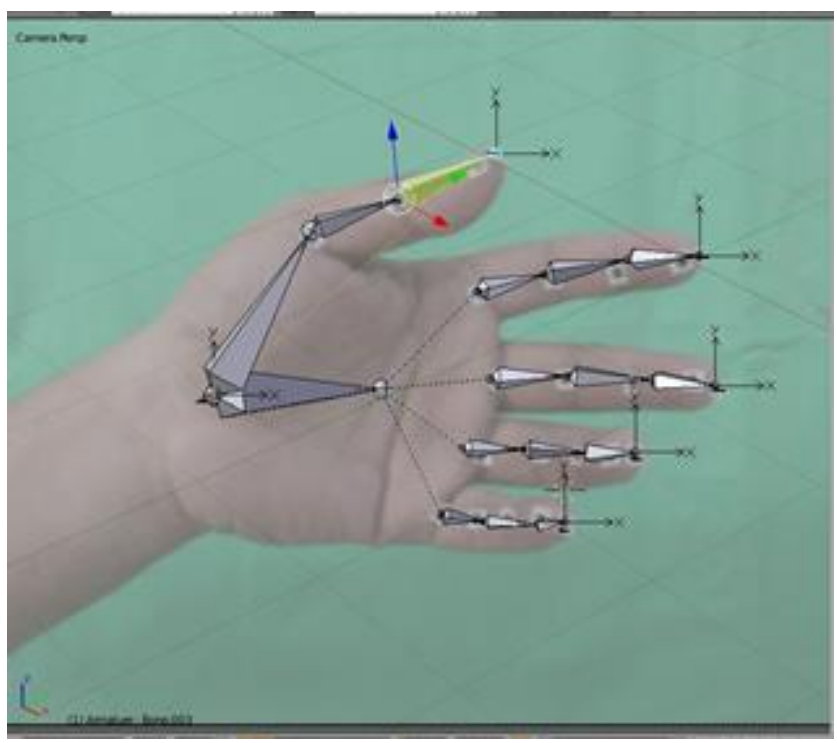

Gambar 8 Prose penghubungan

manual oleh animator. 2) Pergerakan animasi objek tangan 3D harus sesuai dengan referensi pergerakan tangan rekaman video. 3). Pergerakan sendi - sendi karakter modeling 3D harus sesuai dengan pergerakan sendi tangan manusia. 4) Durasi waktu harus sama dengan durasi referensi video rekaman. 5) Pergerakan harus melibatkan multilayer. 6) Pergerakan menggunakan inverse kinematics. 7) Penanda seminimal mungkin. 8) Penggunaan Degree Of Freedom. Setiap kriterian tersebut digunakan untuk empat gerakan yang berbeda. Dengan penggunaan gerakan yang berbeda tersebut dimaksudkan untuk dapat dilihat hasilnya pada setiap gerakan yang berbeda. Dari beberapa gerakan yang dujikan penulis berharap memenuhi kreteria fungsionalyang akan diujikan.

\section{- Analisis Hasil Rancangan}

Pengujian yang penulis lakukan terhadap karakter dan gerakan menunjukkan tingkat keberhasilan sesuai dengan fungsional dengan baik. Untuk mendapatkan hasil pengujian yang objektif, penulis memberikan kesempatan kepada responden untuk melakukan pengujian terhadap fung sionalitas gerakan. Responden yang melakukan pengujian adalah praktisi dan mentor dan guru dalam bidang animasi. Peniliti mengambil responden sebanyak tiga orang, dari ketiga responden yang ahli dibidang animasi tersebut diharapkan hasil pengujian yang didapat secara objektif.

Dari hasil yang telah didapat, penulis menganalisis tingkat keberhasilan model gerakan disesuaikan dengan fungsionalitas. Analisa ini memberikan penjelasan tentang bagaimana menggunakan motion tracking yang baik dan bagaimana untuk pengembangan kedepannya. Berikut ini hasil dari masing - masing gerakan yang telah diujikan:
Tabel 1

Hasil Testing Gerakan Acak

\begin{tabular}{|c|l|l|}
\hline No. & \multicolumn{1}{|c|}{ Tes Fungsional } & \multicolumn{1}{|c|}{$\begin{array}{c}\text { Tingkat } \\
\text { Keberhasilan }\end{array}$} \\
\hline 1. & Keyframe Otomatis & $100 \%$ \\
\hline 2. & $\begin{array}{l}\text { Kesesuaian pergerakan dengan } \\
\text { referensi }\end{array}$ & $100 \%$ \\
\hline 3. & Kesesuaian pergerakan sendi & $95 \%$ \\
\hline 4. & Persamaan waktu durasi waktu & $100 \%$ \\
\hline 5. & $\begin{array}{l}\text { Pergerakan melibatkan } \\
\text { multilayer }\end{array}$ & $100 \%$ \\
\hline 6. & Penggunaan inverse kinematics & $100 \%$ \\
\hline 7. & Penggunaan penanda minimal & $100 \%$ \\
\hline 8. & $\begin{array}{l}\text { Penggunaan Degree Of } \\
\text { Freedom }\end{array}$ & $100 \%$ \\
\hline Rata - Rata & $99 \%$ \\
\hline
\end{tabular}

Tabel 2

Hasil Testing Gerakan Menggenggam

\begin{tabular}{|c|l|l|}
\hline No. & Tes Fungsional & $\begin{array}{l}\text { Tingkat } \\
\text { Keberhasilan }\end{array}$ \\
\hline 1. & Keyframe Otomatis & $90 \%$ \\
\hline 2. & $\begin{array}{l}\text { Kesesuaian pergerakan dengan } \\
\text { referensi }\end{array}$ & $100 \%$ \\
\hline 3. & Kesesuaian pergerakan sendi & $95 \%$ \\
\hline 4. & Persamaan waktu durasi waktu & $90 \%$ \\
\hline 5. & $\begin{array}{l}\text { Pergerakan melibatkan } \\
\text { multilayer }\end{array}$ & $100 \%$ \\
\hline 6. & Penggunaan inverse kinematics & $100 \%$ \\
\hline 7. & Penggunaan penanda minimal & $100 \%$ \\
\hline 8. & $\begin{array}{l}\text { Penggunaan Degree Of } \\
\text { Freedom }\end{array}$ & $100 \%$ \\
\hline Rata - Rata & $97 \%$ \\
\hline
\end{tabular}

Tabel 3

Hasil Testing Gerakan Membawa

\begin{tabular}{|c|l|l|}
\hline No. & Tes Fungsional & $\begin{array}{l}\text { Tingkat } \\
\text { Keberhasilan }\end{array}$ \\
\hline 1. & Keyframe Otomatis & $100 \%$ \\
\hline 2. & $\begin{array}{l}\text { Kesesuaian pergerakan } \\
\text { dengan referensi }\end{array}$ & $100 \%$ \\
\hline 3. & $\begin{array}{l}\text { Kesesuaian pergerakan } \\
\text { sendi }\end{array}$ & $95 \%$ \\
\hline 4. & $\begin{array}{l}\text { Persamaan waktu durasi } \\
\text { waktu }\end{array}$ & $100 \%$ \\
\hline 5. & $\begin{array}{l}\text { Pergerakan melibatkan } \\
\text { multilayer }\end{array}$ & $100 \%$ \\
\hline 6. & $\begin{array}{l}\text { Penggunaan inverse } \\
\text { kinematics }\end{array}$ & $100 \%$ \\
\hline 7. & $\begin{array}{l}\text { Penggunaan penanda } \\
\text { minimal }\end{array}$ & $100 \%$ \\
\hline 8. & $\begin{array}{l}\text { Penggunaan Degree Of } \\
\text { Freedom }\end{array}$ & $100 \%$ \\
\hline Rata - Rata & $99 \%$ \\
\hline
\end{tabular}


Tabel 4

Hasil Testing Gerakan Mengambil

\begin{tabular}{|c|l|l|}
\hline No. & Tes Fungsional & $\begin{array}{l}\text { Tingkat } \\
\text { Keberhasilan }\end{array}$ \\
\hline 1. & Keyframe Otomatis & $100 \%$ \\
\hline 2. & $\begin{array}{l}\text { Kesesuaian pergerakan } \\
\text { dengan referensi }\end{array}$ & $100 \%$ \\
\hline 3. & $\begin{array}{l}\text { Kesesuaian pergerakan } \\
\text { sendi }\end{array}$ & $95 \%$ \\
\hline 4. & $\begin{array}{l}\text { Persamaan waktu durasi } \\
\text { waktu }\end{array}$ & $100 \%$ \\
\hline 5. & $\begin{array}{l}\text { Pergerakan melibatkan } \\
\text { multilayer }\end{array}$ & $100 \%$ \\
\hline 6. & $\begin{array}{l}\text { Penggunaan inverse } \\
\text { kinematics }\end{array}$ & $100 \%$ \\
\hline 7. & $\begin{array}{l}\text { Penggunaan penanda } \\
\text { minimal }\end{array}$ & $100 \%$ \\
\hline 8. & $\begin{array}{l}\text { Penggunaan Degree Of } \\
\text { Freedom }\end{array}$ & $100 \%$ \\
\hline Rata - Rata & $99 \%$ \\
\hline
\end{tabular}

\section{KESIMPULAN DAN SARAN}

Penerapan hand tracking untuk menghasilkan animasi 3D dapat dilakukan dan mempercepat proses animasi dari tracer yang dihasilkan. Beberapa titik yang potensial dari 30 marker dalam proses tracer menghasilkan 6 tracer penting. Dengan menggunakan Inverse Kinematics mengurangi kesalahan gerakan animasi keluar dari jalur frame. Sebagai saran untuk penelitian selanjutnya adalah dengan mencoba menggunakan software yang lain.

\section{DAFTAR PUSTAKA}

[1] Sharp, T. et al., 2015. Accurate, Robust, and Flexible Real-time Hand Tracking. In Proceedings of the 33rd Annual ACM Conference on Human Factors in Computing Systems - CHI '15. New York, New York, USA: ACM Press, pp. 3633-3642. Available at: http://dl.acm.org/citation.cfm?id=2702179.

[2] Huang, J. et al., 2016. 6-DOF computation and marker design for magnetic $3 D$ dexterous motion-tracking system. In Proceedings of the 22nd ACM Conference on Virtual Reality Software and Technology - VRST '16. New York, New York, USA: ACM Press, pp. 211-217. Available at http://doi.acm.org/10.1145/2993369.2993387.

[3] Purwanto, A., 2014. Penggunaan Teknik Rotoscoping Dan Motion Tracking Dalam Pembuatan Video. Seminar Nasional Teknologi Informasi dan Multimedia 2014, ISSN : 2302-3805, 8 Februari 2014.

[4] Purwanto, A. \& Purwanto, I.H., 2015. Pemanfaatan Teknik Tracking 2D Pada Pembuatan Pendahuluan Tinjauan Pustaka Metode Penelitian Hasil dan Pembahasan. Jurnal Ilmiah DASI No. 02, 16(2), pp.1218.

[5] Nugraha, H.S., Suyanto, M. \& Sofyan, A.F., 2015. Pembuatan Model Gerakan Animasi 2D Dengan Menggunakan Metode. Seminar Nasional Teknologi
Informasi dan Multimedia 2015, ISSN : 2302-3805, 6-8 Februari 2015, pp.6-8.

[6] Sebastian Schroeder A., Hesse N., Müller-Felber W., Bodensteiner C., Arens M., G. Hofmann U. (2018) Markerless Motion Analysis for Early Detection of Infantile Movement Disorders. In: Eskola H., Väisänen O., Viik J., Hyttinen J. (eds) EMBEC \& NBC 2017. EMBEC 2017, NBC 2017. IFMBE Proceedings, vol 65. Springer, Singapore

[7] Famukhit, M. Linggar, M Suyanto, Sukoco. 2016. "Simulasi Gerak Kepiting Menggunakan Metode Inverse Kinematics". IJNS - Indonesian Journal on Networking and Security. ISSN:2354-6654 (Online). Vol 5, No 1 (2016) 
